INTERNATIONAL JOURNAL OF MULTIDISCIPLINARY RESEARCH AND ANALySis

ISSN(print): 2643-9840, ISSN(online): 2643-9875

Volume 04 Issue 09 September 2021

DOI: 10.47191/ijmra/v4-i9-19, Impact Factor: 6.072

Page No.- 1327-1333

\title{
Thai Adolescent's Scale of Flourishing During the COVID-19 Pandemic Analysed by the Subjective Well-Being (SWB)
}

\author{
Pitsinee Dachapipatkhon ${ }^{1}$, Pitiporn Cholumyai ${ }^{2}$, Supajira Maturossuntorn ${ }^{3}$, Nantapak Onclai ${ }^{4}$, \\ Nattamon Onclai ${ }^{5}$ \\ 1,2,3,4,5Suankularb Wittayalai Rangsit School, Pathum Thani, Thailand 12120
}

\begin{abstract}
The Coronavirus has been introduced to Thailand for almost 2 years. Students were forced to take online classes in order to gain social distance. As it is well known, adolescents had the highest levels of satisfaction with friends and with self. Due to this occurrence, many students are at risk of mental challenges, likely due to unexpected life changes. The research aims to analyze subjective well-being (SWB) and to compare the data to other studies. The Flourishing Scale of 8 uniform questionnaires by Diener et. al. (2009) is used as a measurement to conduct the research as a major research tool in 507 Thai adolescent participants aged 12-19 years old. The level of psychological well-being and respondent's selfperceived success in important areas such as relationships, self-esteem, purpose, and optimism were quantified and performed. The Flourishing Scale scores in relevant research, enable the researchers to signify the contrast in the level of subjective well-being in Thai- adolescents according to the COVID-19 existence. As a result, the mean of the subjective wellbeing of the Flourishing Scale in Thai adolescence was 37.22 which is one of the lowest scores so far compared to the previous research investigated before the pandemic of the Coronavirus. It can be found that young adolescents are showing a decline in psychological resources and strength compared to the previous years which should be carefully inspected by adults and mental health-related professionals.
\end{abstract}

KEYWORDS: Subjective Well-being (SWB), Psychological, Thai adolescents, Flourishing Scale, COVID-19

\section{INTRODUCTION}

When people describe what they desire in life; happiness and well-being is always an indispensable answer. Especially during adolescent years where development is associated with significant somatic and psychosocial [1], many factors have come to play with sensation and responses. On average, adolescents had the highest levels of satisfaction with friends and with self [2]. An increase in subjective well-being (SWB) is shown when they experience more support and involvement from their parents [3]. The SWB is a scientific term of happiness and life satisfaction. People's level of SWB are influenced by both internal factors; such as personality and outlook, and external factors; such as the society in which they live [4]. Despite the studies of what factors are associated with the SWB for students' mental and physical health, there is a lack of quantitative research investigating the psychological well-being of each adolescent individual in Thailand fundamentally. Thus, during the Coronavirus lockdown and the existence of online learning systems, students are at risk of mental challenges, likely due to unexpected life changes [5]. In the current situation, thriving numbers of deceased patients influence the psychological effects that could cause long-term repercussions [6]. Along with many reported suicide cases in the past few days [7,8]. The study is therefore conducted to examine how adolescents in Thailand rate their own happiness levels via a Flourishing Scale of psychological well-being (SWB) [9]. And to look into what factors are associated with the SWB in terms of respondents' view of themselves. In response to numbered scales to indicate their level of satisfaction, positive feelings, and lack of negative affections.

\section{MATERIALS AND METHODS}

\section{A. Participants}

Participants for this study were five hundred and seven young adolescents ages ranged from 12 to 19 and the mean age was $16.40 \pm 1.64$ located in the country of Thailand. In addition to completing the measures described below, participants reported the personality and outlook, and external factors, including their age, gender, domicile, school, religion, family relationship, and financial situational home as a result of COVID-19 pandemic. 
Thai Adolescent's Scale of Flourishing During the COVID-19 Pandemic Analysed by the Subjective Well-Being (SWB)

\section{B. Measures}

Participants are invited via social media platforms and WOM (word-of-mouth) to participate. The questionnaires are made in the form of Google form and shared as links through platforms, such as Twitter, Line, and Instagram - from 11 August - 20 August 2021.

The process of researching involved collecting background information from individuals and using 8 uniform questionnaires to analyse individual's responses through their responses to questions measure of the respondent's self-perceived success. The scale provides a single psychological well-being score allowing us to present, compare, and contrast to other research. The questionnaires involved using the Flourishing scale of psychological well-being (SWB) [9]. The scale includes of 8-items summary, to measure the respondent's Meaning and purpose (Ryff; Seligman) Supportive and rewarding relationships (Ryff; Deci and Ryan) Engaged and interested (Csikszentmihalyi; Ryff; Seligman) Contribute to the well-being of others (Maslow; Ryff; Deci and Ryan) Competency (Ryff; Deci and Ryan) Self-acceptance (Maslow; Ryff) Optimism (Seligman) Being respected (Maslow; Ryff). In an attempt to find a subjective well-being score amongst Thai adolescents during the Coronavirus pandemic. The scale provides a single psychological well-being score. The individual item scales range from 1 (strongly disagree) to 7 (strongly agree). By adding the 8 questionnaires, the lowest possible score was 8 and the highest was 56 . A high score represents a person with many psychological resources and strengths [9]. Consequently, a psychological questionnaire was performed to reveal the SWB score amongst Thai adolescents during the Coronavirus pandemic while having online learning.

Table I. Personal background of participants.

\begin{tabular}{|c|c|c|c|c|c|}
\hline Characteristics & $\mathrm{N}(\%)$ & $\bar{x} \pm S D$ & Characteristics & N (\%) & $\bar{x} \pm S D$ \\
\hline Age (Year) & & & $\begin{array}{l}\text { Financial situation at home, as a result of the } \\
\text { COVID-19 pandemic. }\end{array}$ & & \\
\hline Twelve & $11(2.17)$ & $\begin{array}{l}36.46 \quad \pm \\
10.54\end{array}$ & Not affected & $37(7.30)$ & $\begin{array}{ll}40.24 \quad \pm \\
8.67\end{array}$ \\
\hline Thirteen & $21(4.14)$ & $\begin{array}{ll}37.33 \quad \pm \\
8.77\end{array}$ & Slightly affected in a negative way & $\begin{array}{l}287 \\
(56.61)\end{array}$ & $37.29 \pm 8.3$ \\
\hline Fourteen & $44(8.68)$ & $\begin{array}{ll}34.82 & \pm \\
9.88 & \end{array}$ & Had a huge impact in a negative way & $\begin{array}{l}161 \\
(31.76)\end{array}$ & $36.74 \pm 9$ \\
\hline Fifteen & $50(9.86)$ & $\begin{array}{ll}33.12 \quad \pm \\
7.26\end{array}$ & Slightly affected in a positive way & $10(1.97)$ & $37.2 \pm 6.09$ \\
\hline Sixteen & $\begin{array}{l}100 \\
(19.72)\end{array}$ & $38.3 \pm 8.97$ & Had a huge impact in a positive way & $12(2.37)$ & $\begin{array}{ll}32.83 \quad \pm \\
9.41\end{array}$ \\
\hline Seventeen & $\begin{array}{l}148 \\
(29.19)\end{array}$ & $\begin{array}{l}37.55 \quad \pm \\
8.25\end{array}$ & Family relationship & & \\
\hline Eighteen & $\begin{array}{l}98 \\
(19.33)\end{array}$ & $37.32 \pm 7.5$ & Very close (5) & $\begin{array}{l}170 \\
(33.53)\end{array}$ & $\begin{array}{l}41.18 \\
8.17\end{array}$ \\
\hline Nineteen & $35(6.90)$ & $37.71 \pm 7.6$ & Close (4) & $\begin{array}{l}187 \\
(36.88)\end{array}$ & $\begin{array}{l}37.21 \\
7.46\end{array}$ \\
\hline
\end{tabular}


Thai Adolescent's Scale of Flourishing During the COVID-19 Pandemic Analysed by the Subjective Well-Being (SWB)

\begin{tabular}{|c|c|c|c|c|c|}
\hline Gender & & & Neutral (3) & $\begin{array}{l}120 \\
(23.67)\end{array}$ & $\begin{array}{l}33.42 \\
7.56\end{array}$ \\
\hline Non-binary & $14(2.76)$ & $\begin{array}{ll}35.29 & \pm \\
7.57 & \end{array}$ & Distant (2) & $26(5.13)$ & $31 \pm 8.33$ \\
\hline Genderqueer & $\begin{array}{l}86 \\
(16.96)\end{array}$ & $\begin{array}{ll}33.73 \quad \pm \\
8.42\end{array}$ & Very distant (1) & $4(0.79)$ & $\begin{array}{l}24.5 \\
10.34\end{array}$ \\
\hline Cisgender Female & $\begin{array}{l}335 \\
(66.07)\end{array}$ & $37.63 \pm 8.4$ & Religion & & \\
\hline Cisgender Male & $\begin{array}{l}56 \\
(11.05)\end{array}$ & $\begin{array}{l}41.18 \\
6.64\end{array}$ & None & \begin{tabular}{|l}
74 \\
$(14.60)$
\end{tabular} & $34.1 \pm 8.27$ \\
\hline Transgender & $4(0.79)$ & $29.25 \pm 6.6$ & Muslim & $19(3.75)$ & $\begin{array}{l}40.58 \\
7.86\end{array}$ \\
\hline Others & $12(2.37)$ & $\begin{array}{l}37.33 \\
10.54\end{array}$ & Buddhism & $\begin{array}{l}403 \\
(79.49)\end{array}$ & $\begin{array}{l}37.72 \\
8.32\end{array}$ \\
\hline Domicile & & & Christianity & $9(1.78)$ & $\begin{array}{l}36.11 \\
9.26\end{array}$ \\
\hline $\begin{array}{l}\text { Southern region part of } \\
\text { Thailand }\end{array}$ & $47(9.27)$ & $\begin{array}{l}37.06 \\
8.04\end{array}$ & Others & $2(0.39)$ & $37 \pm 9.9$ \\
\hline $\begin{array}{l}\text { Northern region part of } \\
\text { Thailand }\end{array}$ & $38(7.50)$ & \begin{tabular}{|l|}
36.32 \\
9.19
\end{tabular} & School & & \\
\hline $\begin{array}{l}\text { Northeastern region part } \\
\text { of Thailand }\end{array}$ & 49 (9.66) & $\begin{array}{l}34.76 \\
10.33\end{array}$ & Private school & $\begin{array}{l}69 \\
(13.61)\end{array}$ & $\begin{array}{l}35.77 \\
8.46\end{array}$ \\
\hline $\begin{array}{l}\text { Eastern region part of } \\
\text { Thailand }\end{array}$ & $33(6.51)$ & $\begin{array}{l}36.97 \\
7.23\end{array}$ & Public school & \begin{tabular}{|l}
406 \\
$(80.08)$
\end{tabular} & $\begin{array}{l}37.49 \\
8.38\end{array}$ \\
\hline $\begin{array}{l}\text { Western region part of } \\
\text { Thailand }\end{array}$ & $6(1.18)$ & $41 \pm 6.66$ & Demonstration school & $4(0.79)$ & $\begin{array}{l}34.25 \\
6.08\end{array}$ \\
\hline $\begin{array}{l}\text { Central region part of } \\
\text { Thailand }\end{array}$ & \begin{tabular}{|l}
73 \\
$(14.40)$
\end{tabular} & $\begin{array}{l}36.62 \\
8.77\end{array}$ & University & 17 (3.35) & \begin{tabular}{|l|}
40.41 \\
8.78
\end{tabular} \\
\hline $\begin{array}{l}\text { Bangkok Metropolitan } \\
\text { Region }\end{array}$ & \begin{tabular}{|l}
261 \\
$(51.48)$
\end{tabular} & $\begin{array}{l}37.97 \\
8.06\end{array}$ & Others & $11(2.17)$ & $\begin{array}{l}32.83 \\
9.41\end{array}$ \\
\hline
\end{tabular}

\section{RESULTS}

According to 507 adolescents aged from 12 to 19 years old across the country of Thailand as shown in table 1 . The mean participants' age of the present study was $16.4 \pm 1.64$ years old. The majority of the participants were cisgender female $(\mathrm{N}=335$, $66.07 \%$ ), are living in the Bangkok Metropolitan Region ( $N=261,51.48 \%$ ), the financial situation in a family is slightly affected negatively as a result of the COVID-19 pandemic ( $N=287,56.61 \%)$, has a close relationship within the family ( $N=187$, $36.88 \%)$, and are currently studying in a public school $(\mathrm{N}=406,80.08 \%)$. Additionally, the reliability of the Flourishing Scale in Thai adolescents' version showed good internal consistency with a Cronbach's alpha coefficient of 0.84 . 
Thai Adolescent's Scale of Flourishing During the COVID-19 Pandemic Analysed by the Subjective Well-Being (SWB)

\section{A. Age}

It can be seen that participants aged 16 years old (Mean $=38.30, S D=8.25$ ) meet the highest mean score in the present study, followed by 19 years old (Mean $=37.71, \mathrm{SD}=7.6), 17$ years old (Mean $=37.55, \mathrm{SD}=8.25), 13$ years old $(\mathrm{Mean}=37.33, \mathrm{SD}=$ $8.77)$, and 18 years old (Mean $=37.32, S D=7.5)$, respectively. While adolescents at the age of 15 are at the lowest figure (Mean $=33.12, \mathrm{SD}=7.26)$

B. Gender

Cisgender male (Mean $=41.18, \mathrm{SD}=6.64)$ scored significantly higher than both cisgender female $($ Mean $=31.63, \mathrm{SD}=8.4)$ and any other genders, and the transgender (Mean $=29.25, \mathrm{SD}=6.6$ ) scored at least.

\section{Domicile}

Participants living in the Western Region part of Thailand (Mean $=41.00, \mathrm{SD}=6.66$ ) was by far the highest. Participants in an area of Bangkok Metropolitan Region (Mean $=37.97, \mathrm{SD}=9.06$ ) have minimally higher figures than those who are living in the Southern Region part of Thailand (Mean $=37.06, \mathrm{SD}=8.04$ ).

\section{School}

Participants studying in university (Mean $=40.41, \mathrm{SD}=8.78$ ) had a greater mean score than both public school (Mean $=37.49, \mathrm{SD}$ $=8.38$ ) and private school (Mean $=37.77, \mathrm{SD}=8.46)$.

\section{E. Religion}

According to the data Muslim (Mean $=40.58, \mathrm{SD}=7.86$ ) had greater score in the Flourishing Scale than Buddhism (Mean $=37.72$, $\mathrm{SD}=8.32$ ) and Christianity (Mean $=36.11, \mathrm{SD}=9.26$ ) and the non-religious (Mean $=34.10, \mathrm{SD}=8.27$ ) scored at least.

\section{F. Family relationship}

It can be seen that the intimacy in a family relationship has a connection with the mean score as the very close relationship (Mean $=41.18, \mathrm{SD}=8.17$ ) had the highest mean score of the flourishing scale following by close (Mean $=37.21, \mathrm{SD}=7.46)$, neutral $(\mathrm{Mean}$ $=33.42, \mathrm{SD}=7.56)$, distant (Mean $=31, \mathrm{SD}=8.33$ ), and very distant (Mean $=24.5, \mathrm{SD}=10.34)$, respectively. Financial situation at home, as a result of the COVID-19 pandemic. The non-affected (Mean $=40.24$, SD $=8.67$ ) participants showed a greater score than those affected in a negative way slightly (Mean $=37.29, \mathrm{SD}=8.3$ ) and huge (Mean $=36.74, \mathrm{SD}=9$ ). In addition, it was greater than the participants who had slightly affected in positive way (Mean $=37.2, \mathrm{SD}=6.09)$ and huge affected in positive way $($ Mean $=$ $32.83, \mathrm{SD}=9.41$ ).

\section{Figure Legend}

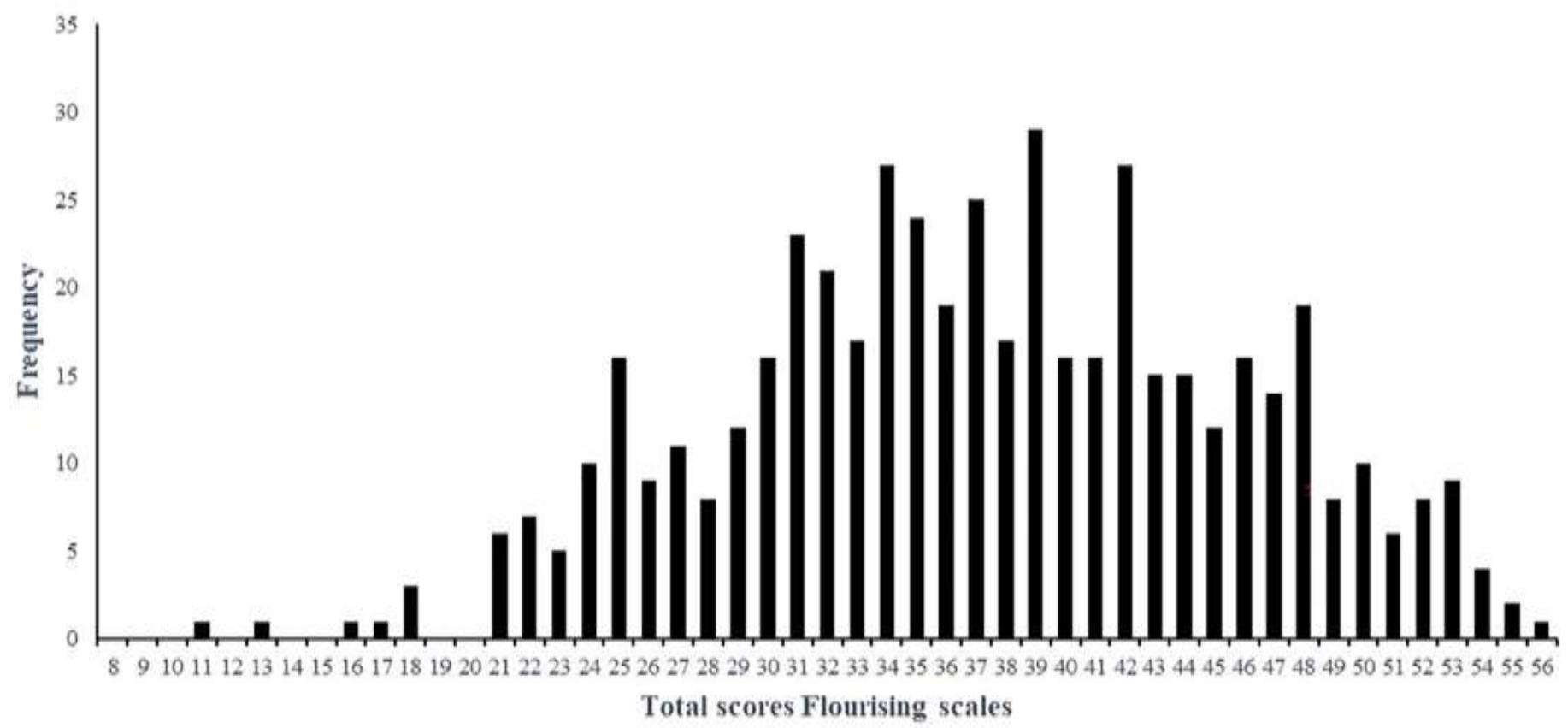

Figure I. Distribution of the total score of the Flourishing Scales

The mean total score on the Flourishing Scale (FS) was 37.22 [SD = 8.45 - which indicates a widespread score in total] with a range from 11 to 56 . Figure 1 shows the distribution of the total FS scores, there was no floor since no participants scored 8, on the other 

(SWB)

hand, the ceiling is presented regarding one individual score 56. The results peaked at a figure of 39 and the majority were skewed towards higher scores on the FS scale (figure 1).

Table II. Items of the Flourishing Scale in Thai adolescents.

\begin{tabular}{|l|l|}
\hline Items & $\bar{x} \pm$ SD \\
\hline I am eager to contribute and support the happiness and well-being of others. (Item 4) & $5.56 \pm 1.33$ \\
\hline I am well-versed and capable in activities that are important to me. (Item 5) & $5.12 \pm 1.47$ \\
\hline I am a good person and live a good life. (Item 6) & $4.73 \pm 1.48$ \\
\hline People respect me. (Item 8) & $4.64 \pm 1.35$ \\
\hline I am an optimistic person. (Item 7) & $4.52 \pm 1.69$ \\
\hline I am engaged and interested in my daily activities. (Item 3) & $4.33 \pm 1.78$ \\
\hline My social relationships are supportive and rewarding. (Item 2) & $4.19 \pm 1.49$ \\
\hline I lead a purposeful and meaningful life. (Item 1) & $4.15 \pm 1.73$ \\
\hline
\end{tabular}

Mean scores on the eight individual items ranged from 4.14 to 5.57 as shown in table 2, on a scale of 1 to 7 . The results surpassed the midpoint of the scale $(M=4.66)$. The highest mean score out of 8 items was item 4 (Mean = 5.56, SD = 1.33): I am eager and support the happiness and well-being of others followed by item 5: I am well-versed and capable in activities that are important to me (Mean $=5.12, \mathrm{SD}=1.47$ ). This shows that Thai adolescents are caring about the fellows' well-being and satisfaction, are engaged, interested, enthusiastic, and enjoying their priority activities temporarily.

\section{DISCUSSION}

Exploratory and confirmatory factor analysis obtained from the sample for the Flourishing Scale, which is consistent with the original study [9]. The findings of this study indicated that the Thai adolescents of the well-being scales have the mean score of $37.22 \pm 8.45$. The previous studies have indicated various mean scores of the Flourishing Scale but mostly reached the mean at more than 40. According to Tong and Wang (2017), Chinese community study aged between 18-85 years old showed the mean of $40.26 \pm 16.79[10]$, which suggested the majority of the sample perceived themselves positively on the main aspects of socialpsychological functioning [11]. Different student samples located in Portuguese and the USA were examined where most means were between 44.5 and 46.7 , respectively $[9,12,13]$. However, except for the one study in Japanese students that found a mean score of 36.6, which suggested that socio-economic and cultural differences may also account for the different results [14]. That is slightly lower than our mean score which was 37.22. Another study in 8 Thai adolescents with major depression disorder from early 2019 until early 2020 have shown a score of Mean $=40.38$, SD $=8.19$ [15], yet with limitations of the number of participants, and were selected from only one medical center in the central region of Thailand. Moreover, all of these past studies were investigated before the pandemic of the COVID-19 which is forecasted to be the main reason cooperating with the decline in the results of subjective well-being in adolescents. The score specifies a connection between each seven factors (gender, age, domicile, the financial situation at home from the effect of the Coronavirus pandemic, the relationship within the family, religion, and school) and the social-psychological well-being contributing with the mean score of the Flourishing Scale in advance. Regarding the data in the family where the financial situation is affected by the COVID-19 pandemic. It can be seen that in non-affected families the scores are substantially greater than those affected families in both negative and positive ways. 


\section{Thai Adolescent's Scale of Flourishing During the COVID-19 Pandemic Analysed by the Subjective Well-Being}

(SWB)

The greater its effect the higher the decrease in the Flourishing Scale score. It can be simplified that the repercussions of the COVID-19 are associated with the subjective well-being in adolescents aged 12-19 years old who are living in Thailand.

\section{CONCLUSION}

The overall findings of this study revealed that the Psychological Well-Being of Thai adolescents during the existence of the COVID19 were skewed towards higher average scores on the FS scale but are at risk of experiencing difficulties

psychologically. Due to a decrease in the SWB of the Flourishing Scale $(M=37.22)$ when compared to the previous reports $(M=$ 44.5-46.7). In brief, the results may have provided directions to stipulate that the mental health and well-being of Thai adolescents has decreased in tendency during the COVID-19 pandemic and should be taken into account for the exact purpose of engaging mental health awareness in Thai society.

\section{ACKNOWLEDGEMENTS}

We would like to express our sincere thanks to our research advisor, Prof. Warawut Chulalaksananukul, Ph.D together with Phawadee Buathong, Ph.D, and Nuttha Chuengcharoenphanich from Faculty of Science, Chulalongkorn University (Thailand) for their invaluable help and constant encouragement throughout the course of this research. In addition, we are grateful for the mathematics teacher: Juthamas Siangkhio for suggestions and all her guidance. Finally, we most gratefully acknowledge our colleagues and people who have willingly helped us out with their abilities.

\section{REFERENCES}

1) Goldbeck L, Schmitz T, Besier T, Herschbach P, Henrich G. Life satisfaction decreases during adolescence. Qual. Life Res. 2007;16:969-979.

2) Antaramian S, Huebner E, Valois R. Adolescent life satisfaction. Appl Psychol. 2008;57:112-126.

3) Bergold S, Steinmayr R. Personality and intelligence interact in the prediction of academic achievement. J. Intell. 2018;6:118.

4) Diener E. Happiness: The science of subjective well-being. Noba textbook series: Psychology. Champaign, IL: DEF; 2021. pp. 1-20.

5) Jiang N, Yan-Li S, Pamanee K, Sriyanto J. Depression, anxiety, and stress during the COVID-19 pandemic: Comparison among higher education students in four countries in the Asia-Pacific region. J. Popul. Soc. Stud. 2021;29:370-383.

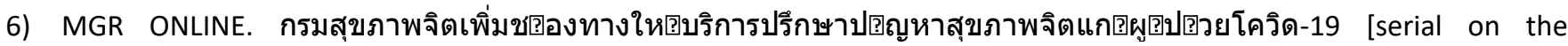
internet]. $2021 \mathrm{Jul}$ [cited $2021 \mathrm{Jul}$ 21]. Available from: https://mgronline.com/uptodate/detail/9640000071278 7. PPTV

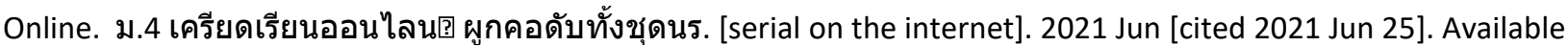

7) from:https://www.pptvhd36.com/news/\%E0\%B8\%AD\%E0\%B8\%B2\%E0\%B8\%8A\%E0\%B8\%8D\%E0\%B8\%B2\%E0\%B8\%81 \%Е0\%B8\%A3\%Е0\%B8\%A3\%E0\%B8\%A1/150211

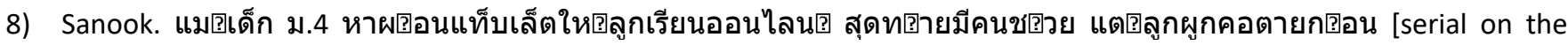
internet]. $2021 \mathrm{Jul}$ [cited $2021 \mathrm{Jul}$ 3]. Available from: https://www.sanook.com/news/8406430/

9) Diener E, Wirtz D, Biswas-Diener R, Tov W, Kim-Prieto C, Choi D. et.al. New measures of well-being: Flourishing and positive and negative feelings; 2009. pp. 247-266.

10) Tong $K$, Wang $Y$. Validation of the flourishing scale and scale of positive and negative experience in a Chinese community sample. PLoS One 2017;12:1-10.

11) Schotanus-Dijkstra M, Klooster P, Drossaert C, Pieterse M, Bolier L, Walburg J. et.al. Validation of the flourishing scale in a sample of people with suboptimal levels of mental well-being. BMC Psychol 2016;4:1-10.

12) Howell A, Buro K. Measuring and predicting student well-being: Further evidence in support of the flourishing scale and the scale of positive and negative experiences. Soc. Indic. Res. 2014;121:903-915.

13) Silva A, Caetano A. Validation of the flourishing scale and scale of positive and negative experience in Portugal. Soc. Indic. Res. 2011;110:469-478.

14) Katsunori S. Reliability and validity of Japanese versions of the flourishing scale and the scale of positive and negative experience. Soc. Indic. Res. 2014;118:601-615.

15) Sakunpong N, Ritkumrop K. Psychometric properties of the Thai version psychological well-being scale and the factors related to among Thai patients with major depressive disorder. Depress Res Treat 2021;2021:1-7. 
Thai Adolescent's Scale of Flourishing During the COVID-19 Pandemic Analysed by the Subjective Well-Being (SWB)

\section{APPENDIX}

Psychological Well-Being Scale (PWB)

Copyright by Ed Diener and Robert Biswas-Diener, January 2009.

Below are 8 statements with which you may agree or disagree. Using the 1-7 scale below, indicate your agreement with each item by indicating that response for each statement.

7 Strongly agree

6 Agree

5 Slightly agree

4 Mixed or neither agree nor disagree

3 Slightly disagree

2 Disagree

1 Strongly disagree

I lead a purposeful and meaningful life.

My social relationships are supportive and rewarding.

I am engaged and interested in my daily activities

I actively contribute to the happiness and well-being of others

I am competent and capable in the activities that are important to me

I am a good person and live a good life

I am optimistic about my future

People respect me

Scoring: Add the responses, varying from 1 to 7, for all eight items. The possible range of scores is from 8 (lowest possible) to 56 (highest PWB possible). A high score represents a person with many psychological resources and strengths. 